\title{
Degradation of Total Organic Carbon (TOC) and Chemical Oxygen Demand (COD) in petroleum wastewater by solar Photo-Fenton process
}

\author{
Aljuboury D.A.D.A. ${ }^{1,}{ }^{*}$, Palaniandy P. ${ }^{1}$, Abdul Aziz H.B. ${ }^{1}$ and Feroz S. ${ }^{2}$ \\ ${ }^{1}$ School of Civil Engineering, Universiti Sains Malaysia, Malaysia \\ ${ }^{2}$ Caledonian College of Engineering, Oman. \\ Received: 01/01/2017, Accepted: 28/02/2017, Available online: 19/10/2017 \\ *to whom all correspondence should be addressed: e-mail: msc.dheeaa@yahoo.com
}

\begin{abstract}
The aim of this study is to investigate the performance of solar photo-Fenton process $\left(\mathrm{H}_{2} \mathrm{O}_{2} / \mathrm{Fe}^{2+} / \mathrm{Solar}\right)$ to treat petroleum wastewater from Sohar oil Refinery, Oman. The effect of operating conditions such as $\mathrm{pH}$, reaction time, Fenton ratio, and Fenton reagent concentrations are investigated. The obtained optimum conditions include $\mathrm{H}_{2} \mathrm{O}_{2}$ dosage $\left(1 \mathrm{~g} \mathrm{~L}^{-1}\right), \mathrm{Fe}^{+2}$ dosage $\left(0.08 \mathrm{~g} \mathrm{~L}^{-1}\right), \mathrm{pH}(3)$ and reaction time (180 $\mathrm{min})$. TOC and COD removal rates are $64 \%$ and $78 \%$, respectively. However, the photolytic process was less efficient in the petroleum wastewater treatment, achieving an $11.5 \%$ and $9 \%$ of COD and TOC removals, respectively. The solar photo-Fenton process has well efficient for petroleum wastewater treatment in the acidic conditions and more economic by free energy.
\end{abstract}

Keywords: Solar Photo-Fenton; Petroleum wastewater; Chemical oxygen demand (COD); Total Organic Carbon (TOC).

\section{Introduction}

Large amounts of water are used in the petroleum refinery activity and, consequently, significant volumes of petroleum wastewater are generated. Recently, one of the major problems facing industrialized nations is contamination of the environment by hazardous chemicals. A wide range of pollutants compounds are detected in petroleum wastewater in Sohar Oil Refinery, so, the elimination of these chemicals from petroleum wastewater is presently one of the most important aspects of pollution control in Oman. Advanced oxidation processes (AOPs) have capability of rapid degradation of recalcitrant pollutants in the aquatic environment. Remediation of hazardous substances is attributed to hydroxyl radical, which exhibits reactivity toward organic. AOPs may be used in petroleum wastewater treatment for overall organic content reduction (COD), specific pollutant destruction, sludge treatment, increasing bioavailability of recalcitrant organics and color and odor reduction (Tony et al., 2012). One of the most important advanced oxidation processes (AOPs) is photo-Fenton process. There are two Fenton's reaction categories: the standard Fenton reaction between hydrogen peroxide and $\mathrm{Fe}^{+2}$ ions in solution, and the Fenton-like reaction where hydrogen peroxide reacts with $\mathrm{Fe}^{+3}$ or immobilized oxides (Yeh et al., 2008). In the presence of light, Fenton's reaction promotes the so-called photo-Fenton process and a higher quantity of $\cdot \mathrm{OH}$ is produced. This is achieved using low-energy photons in the visible light spectrum, such as those generated by sunlight, making this technique economically viable (Torrades et al., 2004). In comparison with other AOPs, the photo-Fenton's reaction presents some advantages, for example (Kositzia et al., 2004) showed the solar photo-Fenton process appears to be more efficient for synthetic municipal wastewater in comparison to the $\mathrm{TiO}_{2}$ /oxidant system. These advantages because $\mathrm{H}_{2} \mathrm{O}_{2}$ slowly decomposed into oxygen and water. In addition, the abundance, lack of toxicity and ease of removal from water makes $\mathrm{Fe}^{2+}$ the most commonly used transition metal for Fenton's reaction applications (Badawy and Ali, 2006). Moreover, the generation of harmful by-products associated with Fenton's reaction applications is noticeably lower compared to some other AOPs (Morais and Zamora, 2005). The analysis of published papers on this field shows a large variation on reagents consumption and the amount of oxidable substances present in the waste water is a fundamental factor, which determines the necessary supply of reagents. However, an appropriate design of the photo-Fenton reactor and the utilization of a more efficient radiation system would contribute to improve process performance and, consequently, reduce reagents consumption. A number of studies have been conducted, showing that the combination of iron and hydrogen peroxide in the presence of light called photo-Fenton's reaction is an effective oxidant for a wide variety of organic substrates. Coelho et al., (2006) reported that the photoFenton process was able to improve the DOC removal in a short period of time from Sourwater which was a specific stream of petroleum refineries and the maximum DOC removal attained was $87 \%$. Previous work by Tony et al., 
(2012) used the photo-Fenton method for the oil-refinery wastewater achieved approximately 50\% COD removal and the photo-Fenton parametric concentrations to maximize COD removal were optimized: $\mathrm{pH}=3, \mathrm{H}_{2} \mathrm{O}_{2}=400 \mathrm{mg} / \mathrm{L}$, and $\mathrm{Fe}^{2+}=40 \mathrm{mg} / \mathrm{L}$. Rossiter et al., (2013) showed that polycyclic aromatic hydrocarbons and aromaticity removal of approximately 92.7 and $96.2 \%$, respectively, from petroleum-extraction wastewater were obtained by a photo-Fenton like process after $7 \mathrm{~h}$ of sunlight exposure and photo-Fenton process using sunlight achieved $53 \%$ COD removal.

The main aims for this study are as follows:

- To investigate the performance of solar photoFenton in petroleum wastewater treatment.

- To determine the optimum operational conditions of the proposed method.

- To compare the proposed method with the previous works.

\section{Materials and methods}

\subsection{Wastewater Characterization}

The physicochemical characteristic of the petroleum wastewater from SOR are summarized in Table 1. Samples of the petroleum wastewater were collected on different days. Samples were transferred to the laboratory and stored under refrigeration $\left(4{ }^{\circ} \mathrm{C}\right)$ until use. Samples were characterized before the experiments to obtain their chemical and physical properties. The petroleum wastewater characterization was determined by the $\mathrm{pH}$, COD, and TOC, which were quite high. This type of petroleum wastewater can be categorized as very dangerous on the environment and it excesses of the standard discharge limits for COD and TOC due to the presence of high organic substances.

Table 1. Characteristics of the petroleum wastewater from SOR

\begin{tabular}{|c|c|c|c|c|}
\hline No & Parameter & $\begin{array}{c}\text { Range of concentrations in petroleum } \\
\text { wastewater }\end{array}$ & Average & $\begin{array}{l}\text { The standard discharge } \\
\text { limit* }\end{array}$ \\
\hline 1 & $\mathrm{pH}$ & $6-8$ & 7 & $6<\mathrm{pH}>9$ \\
\hline 2 & Conductivity (Micro S/cm) & $2600-3950$ & 3275 & $<2700$ \\
\hline 3 & $\operatorname{TDS}(\mathrm{ppm})$ & $1200-1500$ & 1350 & $<2000$ \\
\hline 4 & TOC(ppm) & $220-265$ & 243 & $<75$ \\
\hline 5 & $\mathrm{COD}(\mathrm{ppm})$ & $550-1600$ & 1075 & $<200$ \\
\hline 6 & D.O. (ppm) & $0.6-2.9$ & 1.75 & $>5$ \\
\hline \multirow[t]{2}{*}{7} & Phenol (ppm) & $70-90$ & 80 & 0.001 \\
\hline & Oil (ppm) & $15-22$ & 19 & 0.001 \\
\hline 8 & Iron (ppm) & $<0.01$ & $<0.01$ & 2 \\
\hline 9 & Sulfite(ppm) & $12-15$ & 13.5 & 1.0 \\
\hline
\end{tabular}

*Wastewater discharge standard of Oman (2005)

\subsection{Materials}

Samples of the petroleum wastewater are collected from Sohar oil refinery, Oman. Hydrogen peroxide $\left(\mathrm{H}_{2} \mathrm{O}_{2}\right)(35 \%$ $(v / v))$ and ferrous sulfate are supplied by EMPROVE Exp (USA). Sulfuric acid (95-97\%) and sodium hydroxide (50\%) are used to adjust the $\mathrm{pH}$ to the desired values.

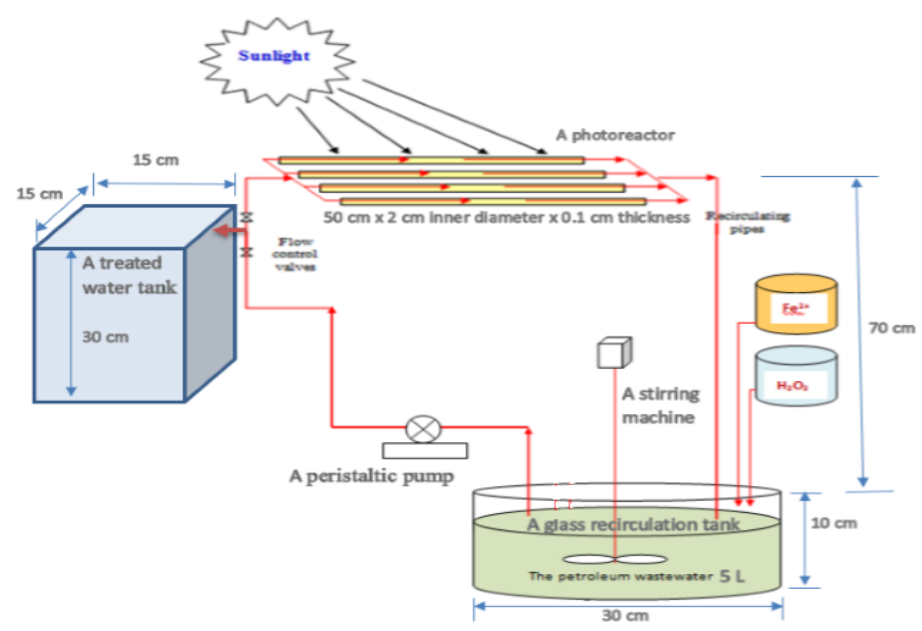

Figure 1. A sketch of the solar photo-Fenton process

\subsection{Experimental procedure}

A schematic design of the solar photo-Fenton process is shown in Figure 1. It consisted of a glass recirculation tank
(7 L), which was subjected to stirring to maintain a wellmixed solution during the experiments, connected with the tubular solar reactor ( 9 tubes $(50 \mathrm{~cm}$ length $\times 2 \mathrm{~cm}$ inner diameter $\times 0.1 \mathrm{~cm}$ thickness)) in order to increase the 
surface area exposed to sunlight according to preliminary study and literature (Senthilkumar and Aljoubory, 2014). The solution was re-circulated through the reactor at a flow rate of about $1.5 \mathrm{~L} / \mathrm{min}$ (according to preliminary study) by means of a peristaltic pump (model; PEROCOM N-M PR2003). The chemical materials were added in a glass recirculation tank in this process. The $\mathrm{pH}$ of petroleum wastewater samples was used between 2 and 9 according to preliminary study and literature (Chu et al., 2012). The photoreactor operated under exposure category of very high (8-11) according to a UV-index by a global UV radiometer (KIPP \& ZONEN).

Several sets of experiments were carried out to evaluate the effectiveness of this process to treat the petroleum wastewater and investigate the influence of important operating parameters, including Fenton ratio, Fenton reagents dosages, $\mathrm{pH}$ and reaction time on removal efficiencies of TOC and COD from this type of wastewater.

\subsection{Analyses}

The Chemical Oxygen Demand (COD) for the petroleum waste water samples is measured by using a COD Photometer (manufactured by CHEMetrics) and their Total Organic Carbon (TOC) by using a TOC Analyzer (manufactured by SHIMADZU (TOC-LCSH/CSN)). In addition, the $\mathrm{pH}$ of the samples is measured by using a Water portable meter (model PCD650, EUTECH). Before each analysis, samples are filtered by filter papers $(0.22 \mu \mathrm{m}$ Millipore Durapore membrane, 40 Ashless, Diameter 150 $\mathrm{mm}$ ) to remove precipitated iron-containing species. Solar ultraviolet radiation (UV) was measured by a global UV radiometer (model: KIPP \& ZONEN, ISO 17166:1999/CIE S007/E-1998). The UV-Index is calculated as follow:

The output voltage $\left(v \mathrm{~m}^{-1}\right)$ from the UV-E radiometer transform it to $\mathrm{W} \mathrm{m} \mathrm{m}^{-2}$ according to instructions of this radiometer model. The Equations ( 1 \& 2) allows calculating the amount of UV intensity received on any surface in the same position with regard to the sun by UV-Index (UVI) as shown in Figure 2.

$$
\begin{aligned}
& \mathrm{R}\left(\mathrm{W} / \mathrm{m}^{2}\right)=0.168 \mathrm{R}(\mathrm{v} / \mathrm{m}) \\
& \mathrm{UVI}=\mathrm{R}\left(\mathrm{W} / \mathrm{m}^{2}\right)^{*} 40\left(\mathrm{~m}^{2} / \mathrm{W}\right)
\end{aligned}
$$

Where:

-UVI is the UV-Index.

$-R$ is the reading $(R)$ in UV radiometer by $\left(W / m^{2}\right)$ unit.

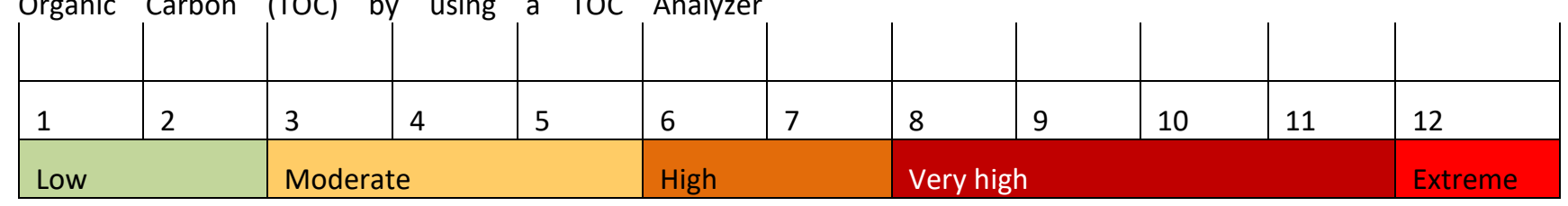

Figure 2. UV-Index which measures UV intensity levels on a scale of 1 to 12

\section{Results and discussion}

\subsection{Effect of $\mathrm{H}_{2} \mathrm{O}_{2}$ to $\mathrm{Fe}^{2+}$ ratio}

Several Fenton ratios $\left(\mathrm{H}_{2} \mathrm{O}_{2} / \mathrm{Fe}^{2+}\right)$, which were 5, 9, 12.5, 25, 50,75 , and 100 , were tested to investigate the optimum value. These experiments were done with optimal $\mathrm{pH} 3$ as shown in Figure 3. The results showed that the optimal ratio of $\mathrm{H}_{2} \mathrm{O}_{2} / \mathrm{Fe}^{2+}$ was 12.5 , and the maximum removal rates of TOC and COD were $64 \%$ and $78 \%$, respectively as shown in Figure 3. The oxidation process led to an increase in the concentration of hydroxyl radicals up to a certain concentration when the hydrogen peroxide ratio increased (Rahman and Al-Malack, 2006). When hydrogen peroxide increased more, it started to react with hydroxyl radicals, acting as a free-radical scavenger (Zazouli et al., 2012).

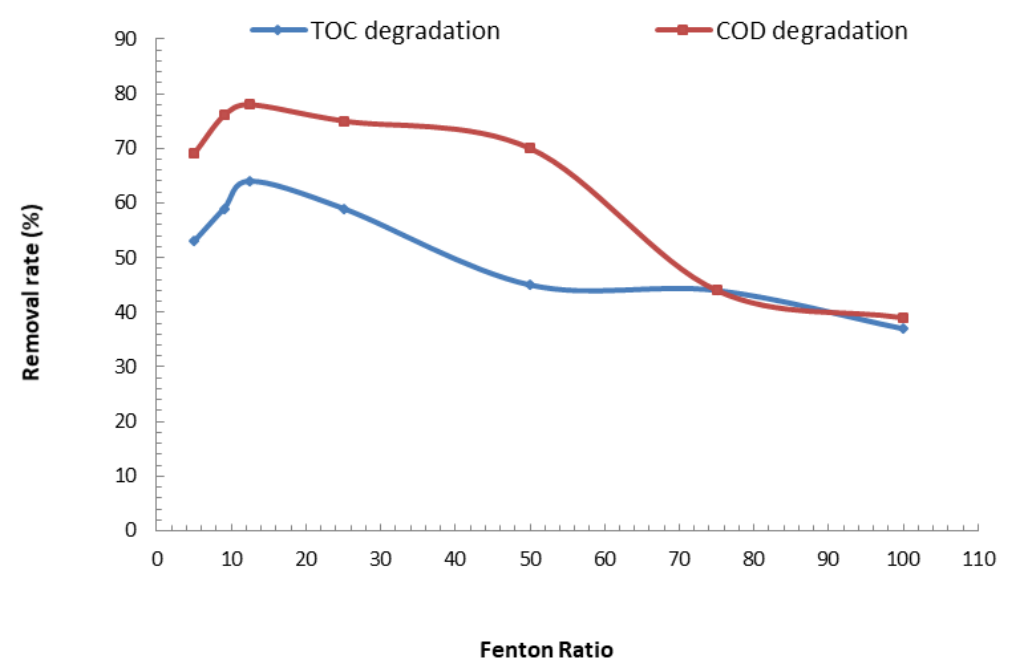

Figure 3. Effect of the $\mathrm{H}_{2} \mathrm{O}_{2} / \mathrm{Fe}^{2+}$ ratio on the degradation rate of TOC and COD by the solar photo-Fenton process in petroleum waste water $(\mathrm{pH}=3 ; 180 \mathrm{~min})$ 


\subsection{Effect of $\mathrm{H}_{2} \mathrm{O}_{2}$ dosage}

The dosing rate of hydrogen peroxide $\left(\mathrm{H}_{2} \mathrm{O}_{2}\right)$ is considered to be one of the most important factors, which should be considered in the solar photo-Fenton process. To determine the optimal $\mathrm{H}_{2} \mathrm{O}_{2}$ dosage to treat the petroleum wastewater by using solar photo-Fenton process and the effect $\mathrm{H}_{2} \mathrm{O}_{2}$ concentration on $\mathrm{COD}$ and TOC removals, the $\mathrm{H}_{2} \mathrm{O}_{2}$ dosages were changed from 1 to $8 \mathrm{~g} \mathrm{~L}^{-1}$ while keeping the concentration of $\mathrm{Fe}^{+2}$ dosage at $0.08 \mathrm{~g} \mathrm{~L}^{-1}$. The results obtained from experiments with varying $\mathrm{H}_{2} \mathrm{O}_{2}$ dosages from 1 to $8 \mathrm{~g} \mathrm{~L}^{-1}$ at $\mathrm{pH} 3$ and $180 \mathrm{~min}$ were illustrated in Figure 4.

The results showed the variation of degradation. The degradation of COD and TOC increased with $\mathrm{H}_{2} \mathrm{O}_{2}$ dosages up to about $1 \mathrm{~g} \mathrm{~L}^{-1}$, while it decreased above this dosage. Thus, the $\mathrm{H}_{2} \mathrm{O}_{2}$ dosage of $1 \mathrm{~g} \mathrm{~L}^{-1}$ was considered the optimal $\mathrm{H}_{2} \mathrm{O}_{2}$ dosage at $\mathrm{pH} 3$ and $180 \mathrm{~min}$. However, when the concentration of $\mathrm{H}_{2} \mathrm{O}_{2}$ exceeded the optimal value, the reaction rates decreased as a result of the so-called scavenging effect of an excess of $\mathrm{H}_{2} \mathrm{O}_{2}$ reacting with hydroxyl radical $(\cdot \mathrm{OH})(\mathrm{Chu}, 2001)$. The excess of $\mathrm{H}_{2} \mathrm{O}_{2}$ reacted with the hydroxyl radical (HO) resulting in the radical hydroperoxyl $\left(\mathrm{HO}_{2}\right)\left(\mathrm{E}^{0}=1.8 \mathrm{~V}\right)$, which has lower oxidation potential than the hydroxyl radical $\left(\mathrm{E}^{0}=2.8 \mathrm{~V}\right)$ (Equation (3)) (Chu and Wong 2004; da Silva et al,. 2015; Dionysiou et al., 2000) and might be attributed to the autodecomposition of $\mathrm{H}_{2} \mathrm{O}_{2}$ to Oxygen $\left(\mathrm{O}_{2}\right)$ and water $\left(\mathrm{H}_{2} \mathrm{O}\right)$ (Equation (4)). Moreover, the recombination of hydroxyl radical $(\cdot \mathrm{OH})$ and the radical hydroperoxyl ( $\left.\mathrm{HO}_{2}\right)$ was increased as shown in Equation (5) (Neyens and Baeyens, 2003);

$$
\begin{aligned}
& \mathrm{H}_{2} \mathrm{O}_{2}+\mathrm{HO} \rightarrow \mathrm{HO}_{2}+\mathrm{H}_{2} \mathrm{O} \\
& \mathrm{H}_{2} \mathrm{O}_{2} \rightarrow \frac{1}{2} \mathrm{O}_{2}+\mathrm{H}_{2} \mathrm{O} \\
& \mathrm{HO}+\mathrm{HO}_{2} \rightarrow+\mathrm{H}_{2} \mathrm{O}+\mathrm{O}_{2}
\end{aligned}
$$

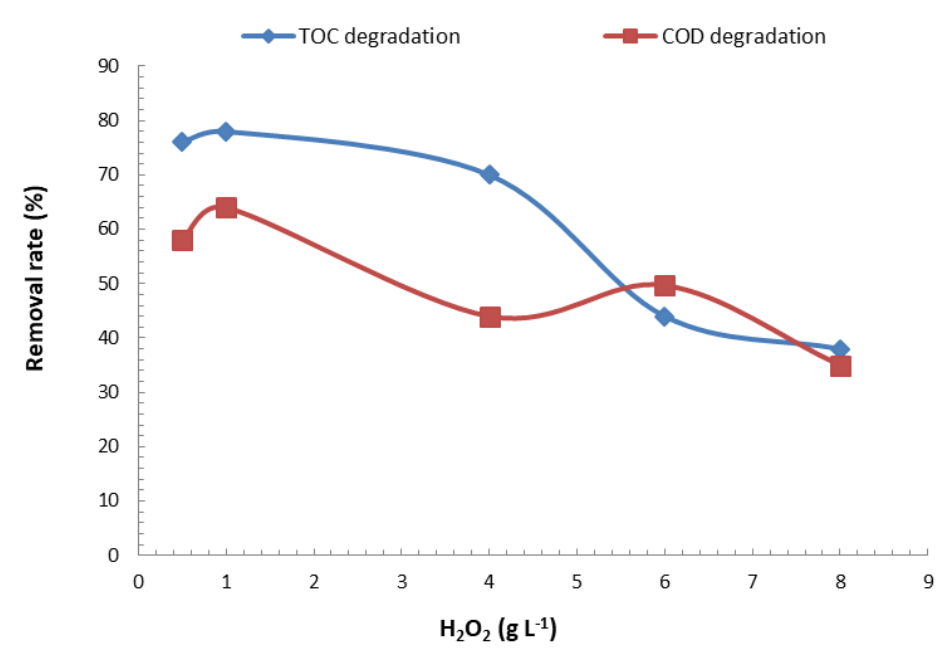

Figure 4. Effect of the $\mathrm{H}_{2} \mathrm{O}_{2}$ dosage on the TOC and COD removals by the solar photo-Fenton processes $\left(\mathrm{pH} 3 ; 0.08 \mathrm{~g} \mathrm{~L}^{-1}\right.$ $\left.\mathrm{Fe}^{+2} ; 180 \mathrm{~min}\right)$

\subsection{Effect of $\mathrm{Fe}^{2+}$ dosage}

The amount of ferrous iron $\left(\mathrm{Fe}^{+2}\right)$ is one of the main parameters, which influence the photo-Fenton processes. To determine the optimal $\mathrm{Fe}^{+2}$ dosage to treat the petroleum wastewater by using solar photo-Fenton process and the effect of $\mathrm{Fe}^{+2}$ concentration on COD and TOC removals, the $\mathrm{Fe}^{+2}$ dosages were changed among 0.04, $0.08,0.11$ and $0.20 \mathrm{~g} \mathrm{~L}^{-1}$ while keeping the $\mathrm{H}_{2} \mathrm{O}_{2}$ dosage at $1 \mathrm{~g} \mathrm{~L}^{-1}$.

The results obtained from experiments with varying $\mathrm{Fe}^{+2}$ dosages among 0.04, 0.08, 0.11 and $0.20 \mathrm{~g} \mathrm{~L}^{-1}$ at $\mathrm{pH} 3$ and 180 min were illustrated in Figure 5. The results showed the variation of degradation. The degradation of COD and TOC increased with $\mathrm{Fe}^{+2}$ dosages up to about $0.08 \mathrm{~g} \mathrm{~L}^{-1}$ while it decreased above this value of dosage. Thus, the $\mathrm{Fe}^{+2}$ dosage of $0.08 \mathrm{~g} \mathrm{~L}^{-1}$ was considered the optimal $\mathrm{Fe}^{+2}$ dosage at $\mathrm{pH} 3$ and $180 \mathrm{~min}$.
However, the extended $\mathrm{Fe}^{+2}$ concentrations above $0.08 \mathrm{~g} / \mathrm{L}$ could not extend COD and TOC removal efficiency due to the excess iron reacted with hydroxyl radicals producing compounds, which inhibited the reaction rates (Equation (6)) (Tony et al., 2009). In addition, the increase of a brown turbidity in the wastewater during the solar photo-Fenton treatment hindered the absorption of the sunlight light required during the photo-Fenton process (Rodrigues et al., 2009).

$$
\mathrm{Fe}^{+2}+\mathrm{OH} \rightarrow \mathrm{Fe}^{3+}+\mathrm{OH}^{-}
$$

It is worth noting that, in the photo-Fenton process, the amounts of $\mathrm{Fe}^{2+}$ ions should be as low as possible for economic and environmental reasons (Ramirez et al., 2007). 


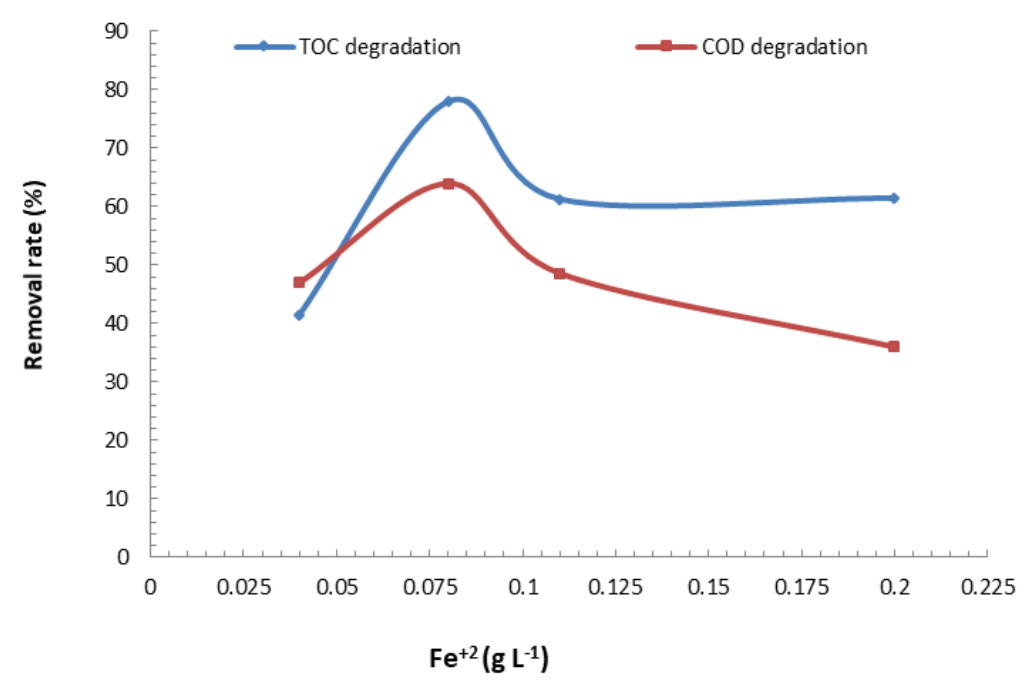

Figure 5. Effect of the ferrous iron $\left(\mathrm{Fe}^{+2}\right)$ dosage on the TOC and COD removals by the solar photo-Fenton processes ( $\left.\mathrm{pH} 3 ; 1 \mathrm{~g} \mathrm{~L}^{-1} \mathrm{H}_{2} \mathrm{O}_{2} ; 180 \mathrm{~min}\right)$

\subsection{Effect of $p H$}

The $\mathrm{pH}$ value influences the generation of hydroxyl radicals and the oxidation efficiency. The $\mathrm{pH}$ significantly affect the solar photo-Fenton process because it influences the activity of both the speciation of iron and hydrogen peroxide decomposition.

The experiments were carried out at a $\mathrm{pH}$ within the range of 2-8. As shown in Figure 6, the results showed that the optimal $\mathrm{pH}$ was 3 at $180 \mathrm{~min}$. The degradation of TOC and COD decreased after $\mathrm{pH} 3$ because the oxidation potential of the hydroxyl radical $(\mathrm{OH})$ decreased with increasing $\mathrm{pH}$ (Lucas and Peres, 2009) and the iron species such as $\mathrm{Fe}^{3+}(\mathrm{OH})_{2}$, which were less photoactive, predominated (Rubio-Clemente et al., 2015). Another reason was the dissociation and autodecomposition of $\mathrm{H}_{2} \mathrm{O}_{2}$ (Badawy and Ali, 2006). In addition, The $\mathrm{pH}$ higher than 3 led to a decrease in the level of free iron ions because of the formation of ferric hydroxides $\left(\mathrm{Fe}(\mathrm{OH})_{3}\right)$, which precipitated (Batista and Nogueira, 2012; Pignatello et al., 2006).

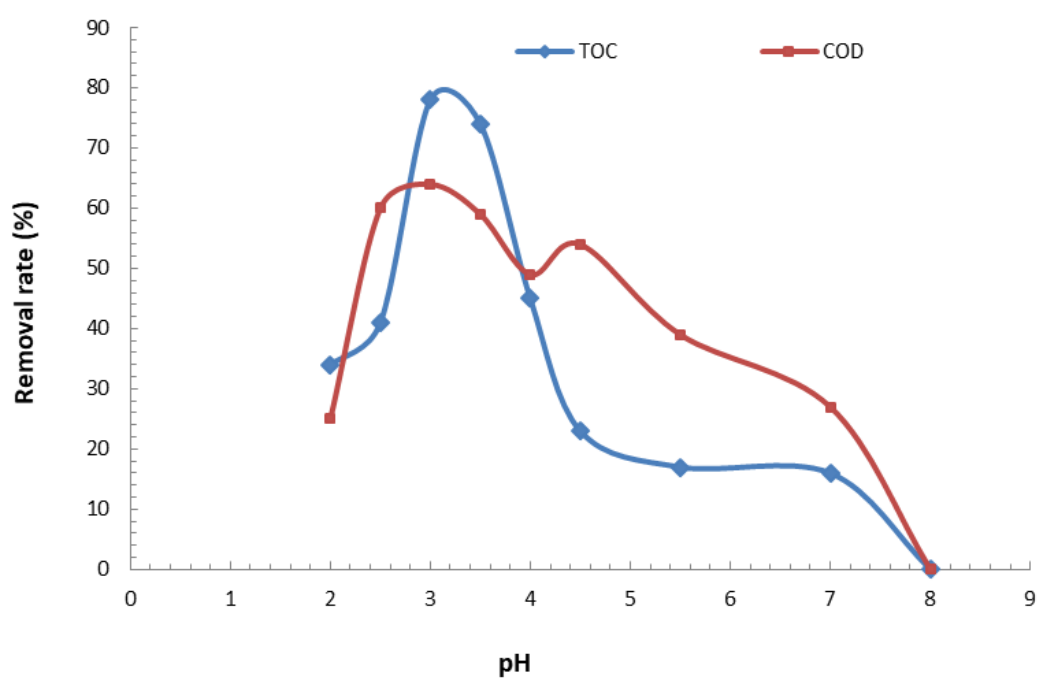

Figure 6. Influence of the initial pH on the degradation rate of TOC and COD by the solar photo-Fenton process

For $\mathrm{pH}$ values below 3 , the reaction of hydrogen peroxide with $\mathrm{Fe}^{2+}$ was seriously affected causing a reduction in hydroxyl radical production due to hydroxyl-radical scavenging by $\mathrm{H}^{+}$ions (Lucas and Peres, 2009). In addition, the activity of the Fenton reagent was reduced in an extremely acidic medium $(\mathrm{pH}<3)$. This could be due to the generation of stable oxonium ions $\left(\mathrm{H}_{3} \mathrm{O}_{2}{ }^{+}\right)$through the solvation of a proton by $\mathrm{H}_{2} \mathrm{O}_{2}$ (Babuponnusami and Muthukumar, 2014; Sun et al., 2008). These observations were in accordance with those reported by Paterlini and Nogueira, (2005) and Kang and Hwang, (2000) who found that an acidic $\mathrm{pH}(2.5-4)$ was optimum for the photoFenton process

\subsection{Effect of reaction time}

The degradation rate of TOC and COD by the solar photoFenton process to treat the petroleum wastewater was monitored continuously during the reaction. As shown in 
Figure 7 , the reaction rate increased with increasing reaction time but after about $120 \mathrm{~min}$, it diminished.

These findings might be explained by the production of hydroxyl radicals increased until $120 \mathrm{~min}$ as shown in Figure 7. Thereafter, the reaction rate diminished as the hydrogen peroxide was consumed, which was the primary source for the generation of the hydroxyl radicals (Tony et al., 2012). In addition, the photo-Fenton reaction needs longer irradiation time since the petroleum wastewater commonly contains high molecular weight and complex structured organic pollutants (da Silva et al., 2015).

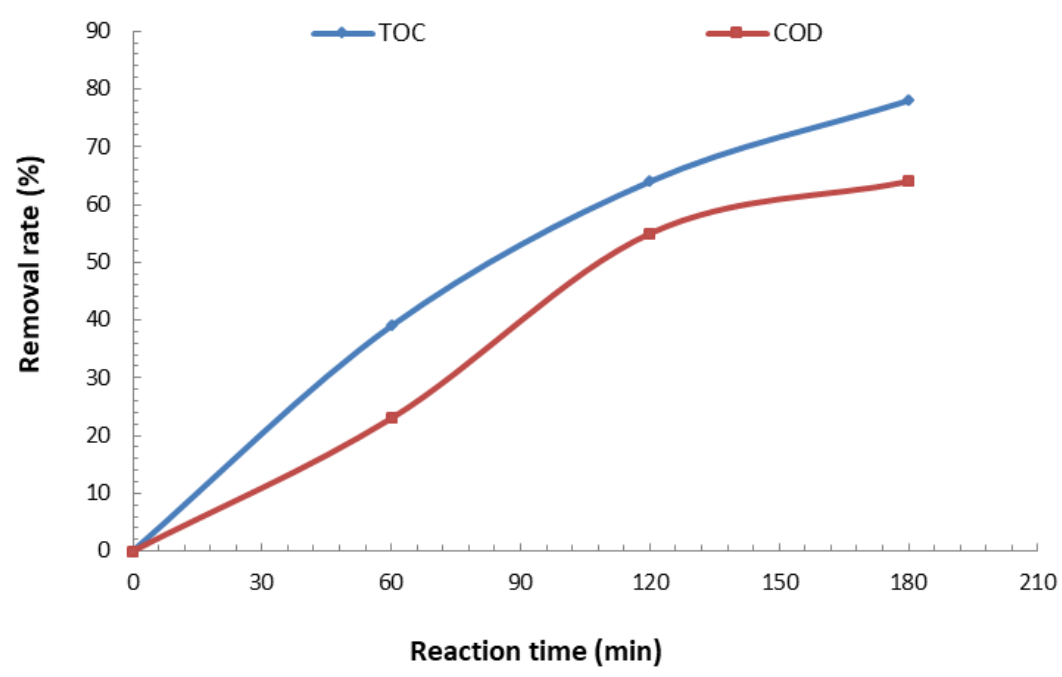

Figure 7. Influence of the reaction time on the degradation rate of TOC and COD by the solar photo-Fenton process

Table 2. Overview of work done in the photo-Fenton application in recent years

\begin{tabular}{|c|c|c|c|c|c|}
\hline No. & The process & Wastewater type & $\begin{array}{l}\text { Removed } \\
\text { material }\end{array}$ & $\begin{array}{l}\text { Max. Removal } \\
\text { efficiency (\%) }\end{array}$ & Ref. \\
\hline 1 & $\mathrm{H}_{2} \mathrm{O}_{2} / \mathrm{Fe}^{2+} /$ Solar & $\begin{array}{c}\text { petroleum-extraction } \\
\text { wastewater }\end{array}$ & COD & $53 \%$ & (da Rocha et al. 2013) \\
\hline 2 & $\mathrm{H}_{2} \mathrm{O}_{2} / \mathrm{Fe}^{+2} / \mathrm{UV}$ & oil-water emulsion & COD & $50 \%$ & Tony et al. (2012) \\
\hline \multirow{2}{*}{3} & $\mathrm{H}_{2} \mathrm{O}_{2} / \mathrm{Fe}^{2+}$ & \multirow{2}{*}{$\begin{array}{c}\begin{array}{c}\text { Semi-aerobic landfill } \\
\text { leachate. }\end{array} \\
\end{array}$} & COD & 58.1 & \multirow{2}{*}{ (Mohajeri et al. 2010) } \\
\hline & $\mathrm{H}_{2} \mathrm{O}_{2} / \mathrm{Fe}^{3+}$ & & Color & 78.3 & \\
\hline \multirow{2}{*}{4} & \multirow{2}{*}{$\mathrm{H}_{2} \mathrm{O}_{2} / \mathrm{Fe}^{2+}$} & \multirow{2}{*}{ Coking wastewater. } & phenol & 95 & \multirow{2}{*}{ (Chu et al. 2012) } \\
\hline & & & COD & 44 & \\
\hline 5 & $\mathrm{H}_{2} \mathrm{O}_{2} / \mathrm{Fe}^{2+}$ & $\begin{array}{l}\text { Water contaminated with } \\
\text { CFVP. }\end{array}$ & CFVP & 95 & (Oliveira et al. 2014) \\
\hline \multirow{3}{*}{6} & \multirow{3}{*}{$\mathrm{H}_{2} \mathrm{O}_{2} / \mathrm{Fe}^{2+}$} & \multirow{3}{*}{ The textile effluent } & COD & 90 & \multirow{3}{*}{ (Karthikeyan et al. 2011) } \\
\hline & & & $\mathrm{BOD}$ & 61 & \\
\hline & & & TOC & 64.1 & \\
\hline 7 & $\mathrm{H}_{2} \mathrm{O}_{2} / \mathrm{Fe}^{2+}$ & Agro-industrial wastewaters & TOC & 58.8 & (Martins et al. 2010) \\
\hline 8 & $\mathrm{H}_{2} \mathrm{O}_{2} / \mathrm{Fe}^{2+}$ & $\begin{array}{c}\text { The pharmaceutical } \\
\text { wastewater }\end{array}$ & COD & 56.4 & (Martí et al. 2003) \\
\hline \multirow{2}{*}{9} & \multirow{2}{*}{$\mathrm{H}_{2} \mathrm{O}_{2} / \mathrm{Fe}^{2+}$} & \multirow{2}{*}{$\begin{array}{c}\text { Water contaminated Direct } \\
\text { Blue } 71\end{array}$} & DB71 dye & 94 & \multirow{2}{*}{ (Ertugay \& Acar 2013) } \\
\hline & & & COD & 50.7 & \\
\hline \multirow{3}{*}{10} & $\mathrm{H}_{2} \mathrm{O}_{2} / \mathrm{Fe}^{2+}$ & \multirow{3}{*}{$\begin{array}{l}\text { Oil recovery industry } \\
\text { wastewater. }\end{array}$} & \multirow{3}{*}{ COD } & 86 & \multirow{3}{*}{ (Dincer et al. 2008) } \\
\hline & $\mathrm{H}_{2} \mathrm{O}_{2} / \mathrm{Fe}^{2+} / \mathrm{UV}$ & & & 81 & \\
\hline & $\mathrm{H}_{2} \mathrm{O}_{2} / \mathrm{UV}$ & & & 39 & \\
\hline 11 & $\mathrm{H}_{2} \mathrm{O}_{2} / \mathrm{Fe}^{2+}$ & $\begin{array}{l}\text { The fish canning industrial } \\
\text { wastewater. }\end{array}$ & DOC & 63 & (Cristóvão et al. 2014) \\
\hline 12 & $\mathrm{H}_{2} \mathrm{O}_{2} / \mathrm{Fe}^{2+}$ & $\begin{array}{c}\text { Active pharmaceutical } \\
\text { wastewaters. }\end{array}$ & COD & 54 & (Hussain et al. 2013) \\
\hline 13 & $\mathrm{H}_{2} \mathrm{O}_{2} / \mathrm{Fe}^{2+}$ & $\begin{array}{c}\text { Real effluent with COD: } \\
1500 \mathrm{mg} / \mathrm{L} .\end{array}$ & COD & 45 & (Kang \& Hwang 2000) \\
\hline \multirow{2}{*}{$\#$} & \multirow{2}{*}{$\mathrm{H}_{2} \mathrm{O}_{2} / \mathrm{Fe}^{2+} / \mathrm{Solar}$} & \multirow{2}{*}{$\begin{array}{l}\text { Petroleum wastewater from } \\
\text { SOR. }\end{array}$} & COD & 74.7 & \multirow{2}{*}{ This study } \\
\hline & & & TOC & 59.3 & \\
\hline
\end{tabular}




\section{Comparison the results with other works}

The results of this research were compared with those of other works that treated the wastewater by using the photo-Fenton method. Comparing this work with the previous works was summarized in the Table 2.

Da Rocha et al., (2013) showed that polycyclic aromatic hydrocarbons and aromaticity removal of approximately 92.7 and $96.2 \%$, respectively, from petroleum-extraction wastewater were obtained by a solar photo-Fenton like process after $420 \mathrm{~min}$ and solar photo-Fenton process achieved 53\% COD removal.

Tony et al., (2012) obtained 50\% COD removal after using $\left(\mathrm{H}_{2} \mathrm{O}_{2} / \mathrm{Fe}^{+2} / \mathrm{UV}\right)$ method under optimal conditions; $\mathrm{pH} 3$, $\mathrm{H}_{2} \mathrm{O}_{2} / \mathrm{Fe}^{+2}$ ratio 10 while the current study revealed that the solar photo-Fenton process in an AOP was more efficient in the petroleum wastewater treatment, achieving a $74.7 \%$
COD removal at conditions; $\mathrm{pH} 3.68, \mathrm{H}_{2} \mathrm{O}_{2} / \mathrm{Fe}^{+2}$ ratio 14 . The maximum of COD removal at $\mathrm{pH} 3.68$ agreed with the results found in the literature for other wastewaters treated by Fenton process, for example, Ertugay and Acar, (2013) indicated that the highest COD removal was determined $50.7 \%$ at $\mathrm{pH} 3$.

\section{Evaluation of the solar photo-Fenton process}

To evaluate the photolytic effect on the COD and TOC removal, the photolytic process experiments were carried out under sunlight. The tubular photo reactor operated under exposure category of very high (8-11) according to a UV-index. The results revealed that the photolytic process was less efficient in the petroleum wastewater treatment, achieving an $11.5 \%$ and $9 \%$ of COD and TOC removals, respectively, at pH 3.68 after $180 \mathrm{~min}$ of solar irradiation as shown in Figure 8.

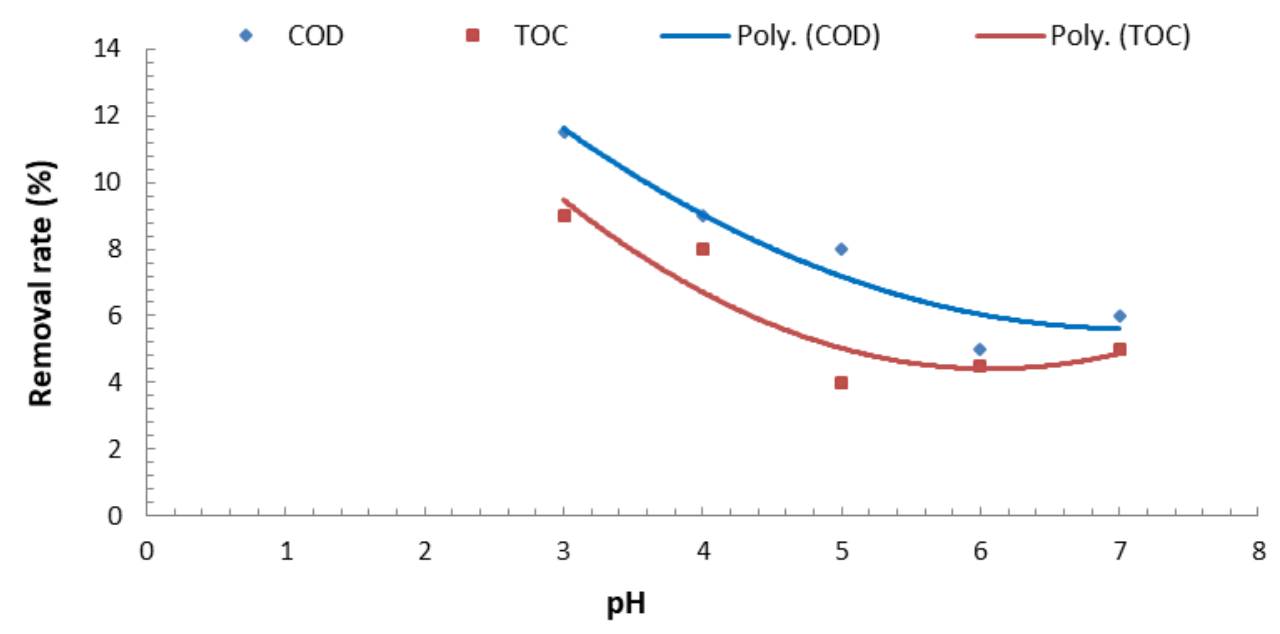

Figure 8. Effect of $\mathrm{pH}$ on the degradation rate of TOC \& COD by the photolytic process at $180 \mathrm{~min}$

Some experiments were carried out by adding $0.85 \mathrm{~g} \mathrm{~L}^{-1}$ Hydrogen peroxide $\left(\mathrm{H}_{2} \mathrm{O}_{2}\right)(35 \%(\mathrm{v} / \mathrm{v}))$ to evaluate the effect of the Hydrogen peroxide $\left(\mathrm{H}_{2} \mathrm{O}_{2}\right)$ with solar radiation. The results revealed that $23 \%$ and $24 \%$ of COD and TOC, respectively, were removed within $180 \mathrm{~min}$ at $\mathrm{pH} 3.68$ as shown in Figure 9. The degradation was attributed to the photochemical cleavage of $\mathrm{H}_{2} \mathrm{O}_{2}$ by solar light absorption resulting to increase rate of production hydroxyl radical $(\bullet \mathrm{OH})$ (Parsons, 2005; Oliveira et al,. 2012).

To evaluate the performance of employing the Fenton process in the absence of solar irradiation to treat petroleum wastewater, the Fenton experiments were carried out with adding $0.85 \mathrm{~g} \mathrm{~L}^{-1}$ hydrogen peroxide $\left(\mathrm{H}_{2} \mathrm{O}_{2}\right)$ $(35 \%(\mathrm{v} / \mathrm{v}))$ and $0.06 \mathrm{~g} \mathrm{~L}^{-1}$ Iron sulfate hydrate $\left(\mathrm{FeO}_{12} \mathrm{~S}_{3}\right)$ at $\mathrm{pH}$ 3.68. As shown in Figure 10, Results of this process indicated that the COD removal was decreased to $61 \% \%$ at $\mathrm{pH} 3.68$ after $180 \mathrm{~min}$, due to the lower generation of hydroxyl radical $(\bullet \mathrm{OH})$.

\section{Conclusions}

- In the present study, the performance of employing of solar photo-Fenton
$\left(\mathrm{H}_{2} \mathrm{O}_{2} / \mathrm{Fe}^{2+} /\right.$ Solar $)$ in the AOP on degradation of TOC and COD from petroleum waste water in Sohar oil refinery in Oman are investigated.

- The general results of this work indicated that the solar photo-Fenton was a practical method to treat petroleum wastewaters, allowing achieved well removal of TOC and COD.

- The obtained optimum conditions include $\mathrm{H}_{2} \mathrm{O}_{2}$ dosage $\left(1 \mathrm{~g} \mathrm{~L}^{-1}\right), \mathrm{Fe}^{+2}$ dosage $\left(0.08 \mathrm{~g} \mathrm{~L}^{-1}\right), \mathrm{pH}(3)$ and reaction time (180 $\mathrm{min})$. TOC and COD removal rates are $64 \%$ and $78 \%$, respectively.

- However, the photolytic process was less efficient in the petroleum wastewater treatment, achieving an $11.5 \%$ and $9 \%$ of COD and TOC removals, respectively.

- The solar photo-Fenton process has well efficient for petroleum wastewater treatment in acidic conditions, achieving a $74.7 \%$ COD removal at $\mathrm{pH}$ $=3.68$, and more economic by free energy. 


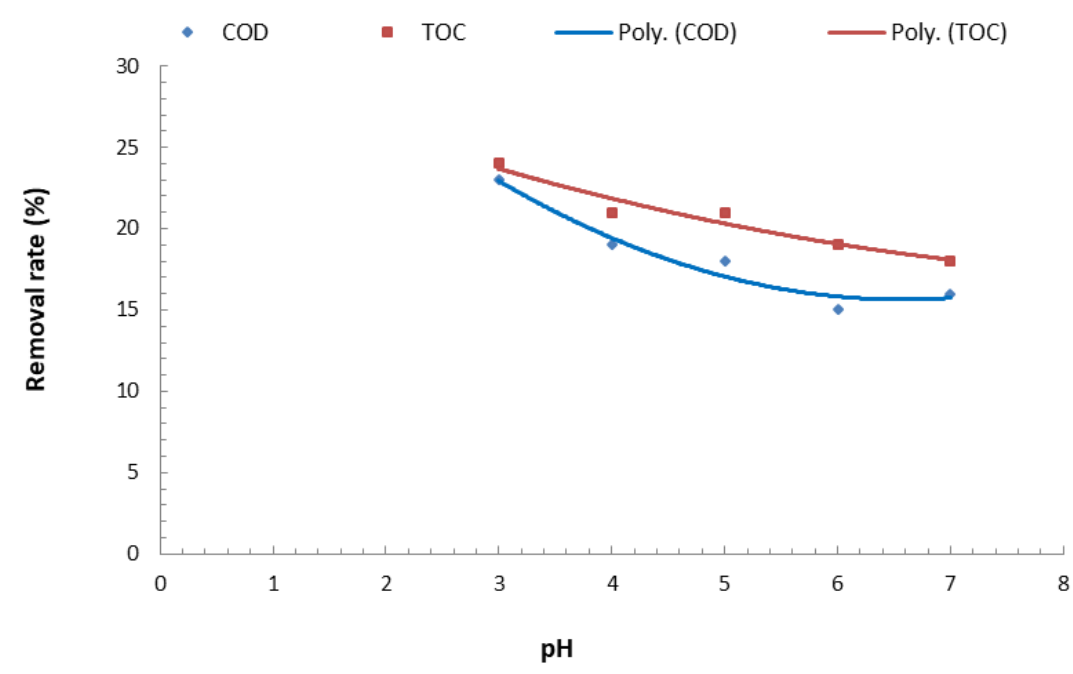

Figure 9. Effect of $\mathrm{pH}$ on the degradation rate of TOC and COD by the $\mathrm{H}_{2} \mathrm{O}_{2} /$ solar process at $180 \mathrm{~min}$

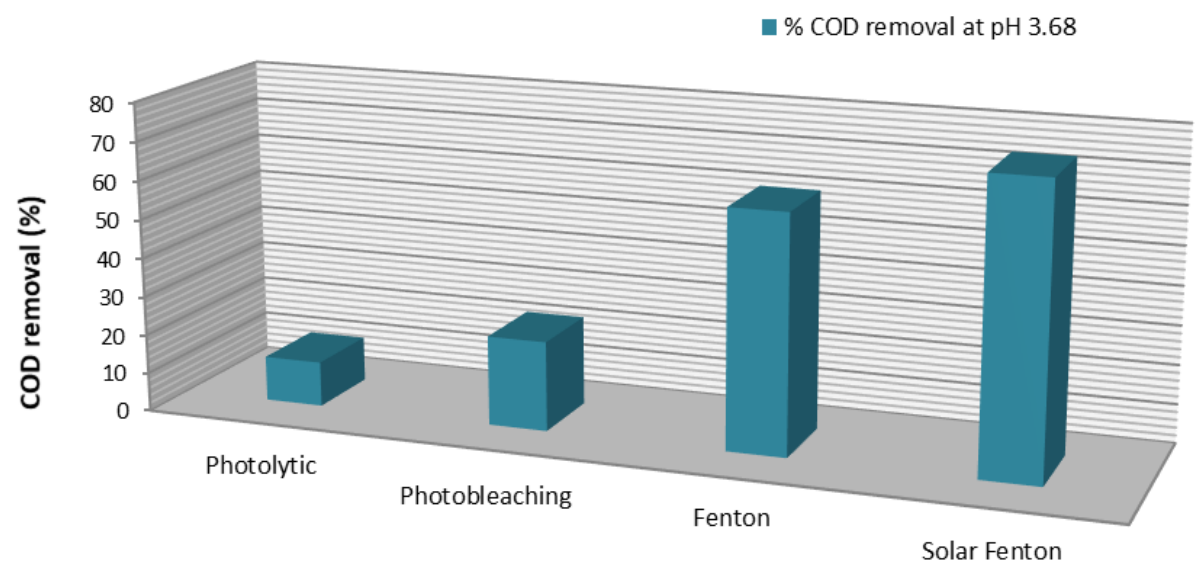

The processes

Figure 10. COD removal from petroleum wastewater under different processes

\section{References}

Aljuboury D.D.A. and Senthilkumar R. (2014), Phenol degradation of industrial wastewater by photocatalysis, J. Innov. Eng., 2(2), 5, 1-10.

Babuponnusami A. and Muthukumar K. (2014) A review on Fenton and improvements to the Fenton process for wastewater treatment, J. Environ. Chem. Eng., 2,557-572.

Badawy M.I. and Ali M. (2006), Fenton's per-oxidation and coagulation processes for the treatment of combined industrial and domestic wastewater, J. Hazard. Mater., 136, 961-966.

Batista A.P.S. and Nogueira R.F.P. (2012) Parameters affecting sulfonamide photo-Fenton degradation iron complexation and substituent group, Journal of Photochemistry and Photobiology A: Chemistry, 232(15), 8-13.

Chu L., Wanga J., Dong J., Liu H. and Sun X. (2012), Treatment of coking wastewater by an advanced Fenton oxidation process using iron powder and hydrogen peroxide, Inter. Chemosphere J., 86, 409-414.

Chu L., Wanga J., Dong J., Liu H. and Sun X. (2012), Treatment of coking wastewater by an advanced Fenton oxidation process using iron powder and hydrogen peroxide, Inter. Chemosphere J., 86, 409-414.

Chu W. (2001), Modeling the quantum yields of herbicide 2, 4-D decay in $\mathrm{UV} / \mathrm{H}_{2} \mathrm{O}_{2}$ process, Chemosphere, 44, 935-941.

Chu W. and Wong C.C. (2004), The photocatalytic degradation of dicamba in $\mathrm{TiO}_{2}$ suspensions with the help of hydrogen peroxide by different near UV irradiations, Water Res, 38, 1037-1043.

Coelho A., Castro A.V., Dezotti M. and Anna G.Jr.L.S. (2006), Treatment of petroleum refinery sourwater by advanced oxidation processes, J. Hazard Mater. B, 137, 178-184.

Cristovao R.O., Goncalves C., Botelho C.M., Martins R.J.E. and Boaventur R.A.R. (2014), Chemical oxidation of fish canning wastewater by Fenton's reagent, J. Environ. Chem. Eng., 2(4), 2372-2376.

Da Rocha O.R.S., Dantas R.F., Duarte M.M.M.B., Duarte M.M.L. and Da Silva V.L. (2013), Solar photo-Fenton treatment of petroleum extraction wastewater, Des. Water Treat., 51, 28-30.

De Morais J.L. and Zamora P.P. (2005), Use of advanced oxidation processes to improve the biodegradability of mature landfill leachates, J. Hazard. Mater., 123, 181-186. 
Dincer A.R., Karakaya N., Gunes E. and Gunes Y. (2008), Removal of COD from oil recovery industry wastewater by the Advanced Oxidation Processes (AOP) based on $\mathrm{H}_{2} \mathrm{O}_{2}$, Glob. N. J., 10, 31-38.

Dionysiou D.D., Suidan M.T., Bekou E., Baudin I. and Lain J.M. (2000), Effect of ionic strength and hydrogen peroxide on the photocatalytic degradation of 4-chlorobenzoic acid in water, Appl. Catal. B: Environ., 26, 153-171.

Ertugay N. and Acar F.N. (2013), Removal of COD and color from Direct Blue 71 azo dye wastewater by Fenton's oxidation: Kinetic study, Arab. J. Chem., in press.

Hussain S., Shaikh S. and Farooqui M. (2013), COD reduction of waste water streams of active pharmaceutical ingredient Atenolol manufacturing unit by advanced oxidation-Fenton process, J. S. Chem. Soc., 17, 2, 199-202.

Kang Y.W. and Hwang K.Y. (2000), Effects of reaction conditions on the oxidation efficiency in the Fenton process, Water Res., 34, 2786-2790.

Karthikeyan S., Titus A., Gnanamani A., Mandal A.B. and Sekaran G. (2011), Treatment of textile wastewater by homogeneous and heterogeneous Fenton oxidation processes, Des. J., 2, 438-445.

Kositzia M., Poulios I., Malato S., Caceres J. and Campos A. (2004), Solar photocatalytic treatment of synthetic municipal wastewater, J. Water Res., 38, 1147-1154.

Lucas M.S. and Peres J.A. (2009), Removal of COD from olive mill wastewater by Fenton's reagent: kinetic study, J. Hazard. Mater., 168, 1253-1259.

Martins R.C., Rossi A.F. and Rosa M. (2010), Fenton's oxidation process for phenolic wastewater remediation and biodegradability enhancement, J. Hazard. Mater., 180, 716-721.

Mohajeri S., Hamidi A.A., Isa M.H., Bashir M.J.K. and Mohajeri L. (2010), Influence of Fenton reagent oxidation on mineralization and decolorization of municipal landfill leachate, J. Environ. Sci. Heal. A, 45, 692-698.

Neyens E. and Baeyens J. (2003), A review of classic Fenton's peroxidation as an advanced oxidation technique, J. Hazard. Mater., 98, 33-50.

Oliveira A., Saggioro E.M., Moreira J.C., Ferreira L.F.V. and Pavesi T. (2012), Solar photochemistry for environmental remediation, Advanced Oxidation Processes for industrial wastewater treatment. INTECH Open Access Publisher.

Oliveira C., Alves A. and Madeira L.M. (2014), Treatment of water networks (waters and deposits) contaminated with chlorfenvinphos by oxidation with Fenton's reagent, Chem. Eng. J., 241, 190-199.

Parson S. (2005) Advanced oxidation processes for water and wastewater treatment. IWA, 86-109.

Paterlini W.C. and Nogueira R.F.P. (2005), Multivariate analysis of Photo-Fenton degradation of the herbicides tebuthiuron, diuron and 2,4-D, Chemosphere, 58, 1107-1116.

Rahman M.M. and Al-Malack M.H. (2006), Performance of a cross flow membrane bioreactor (CF-MBR) when treating refinery wastewater, Des., 191, 16-26.

Ramirez J.H., Maldonado-Hodar F.J., Perez-Cadenas A.F., MorenoCastilla C., Costa C.A. and Madeira L.M. (2007), Azo-dye Orange II degradation by heterogeneous Fenton-like reaction using carbon-Fe catalysts, Appl. Cataly. B: Environ., 75, 312-323.
Rodrigues C., Madeira L. and Boaventura R. (2009), Optimization of the azo dye Procion Red H-EXL degradation by Fenton's reagent using experimental design, J. Hazard. Mater., 164, 987-994.

Rossiter O., Rochaa S., Renato D.F., Marta M.M. and Duarte B. (2013), Solar photo-Fenton treatment of petroleum extraction wastewater, J. Des. Water Treat., 51, 5785-5791.

Rubio-Clemente A., Chica E. and Penuela G.A. (2015), Petrochemical wastewater treatment by photo-Fenton process, Water Air Soil Pollut., 226, 61-79.

Silva S.S., Chiavone-Filho O., Neto E.L.B. and Foletto E.L. (2015), Oil removal from produced water by conjugation of flotation and photo-Fenton processes, J. Environ. Manage., 147, 257-263.

Sun Y., Zhang Y. and Quan X. (2008a), Treatment of petroleum refinery wastewater by microwave-assisted catalytic wet air oxidation under low temperature and low pressure, Separ. Purific. Tech., 62, 565-570.

Tony M.A., Patrick J. and Purcell Yaqian Z. (2012), Oil refinery wastewater treatment using physicochemical, Fenton and Photo-Fenton oxidation processes, J. Environ. Sci. Heal. A., 47, 435-440.

Tony M.A., Zhao Y.Q., Purcell P.J. and El-Sherbiny M.F. (2009), Evaluating the photo-catalytic application of Fenton's reagent augmented with $\mathrm{TiO}_{2}$ and $\mathrm{ZnO}$ for the mineralization of an oilwater emulsion, J. Environ. Sci. Health A, 44(5), 488-493.

Torrades J., Garcia M., Garcia H.J.A, Domenech X. and Peral J. (2004), Decolorization and mineralization of commercial reactive dyes under solar light assisted photo-Fenton conditions, Sol. Energy, 77, 573-581.

Yeh C.K.J., Hsu C.Y., Chiu C.H. and Huang K.L. (2008), Reaction efficiencies and rate constants for the goethite-catalyzed Fenton-like reaction of NAPL-form aromatic hydrocarbons and chloroethylenes, J. Hazard. Mater., 151, 562-569.

Zazouli M.A., Yousefi Z., Eslami A. and Ardebilian M.B. (2012), Municipal solid waste landfill leachate treatment by fenton, photo-fenton and fenton-like processes: Effect of some variables, Iranian J. Environ. Health Sci. Eng., 9(3), 1-9. 